\section{ASTM Standards in Microscopy}

\author{
John J. Friel \\ Chairman of ASTM Committee E04.11 \\ on X-ray and Electron Metallography \\ jjf@pgt.com
}

ASTM International publishes many standards specifically about microscopes and using microscopy. The value of these standards falls into three distinct categories. First, they can be a quick tutorial on how to perform some operation. E 1508, "Standard Guide to Quantitative Analysis by EDS" is only eight pages long and falls into this category. Second, they can be used to standardize a test and reporting method. The methods described in E 1382, "Standard Test Methods for Determining Grain Size by Semiautomatic and Automatic Image Analysis" are examples of procedures that have been agreed upon for many years. Third, standard practices can be used to provide accrediting agencies with evidence of accepted laboratory procedures. E 766 "Standard Practice for Calibrating the Magnification of an SEM" can be used in this way.

The society began over 100 years ago as the American Society for Testing and Materials and issues standard: specifications, test methods, practices, guides, classifications, and terminologies. It consists of technical committees, subcommittees, and task groups. Over the years, the scope of materials covered by ASTM standards has increased greatly, and many standards have been adopted by other nations' standards agencies, and by ISO. All standards are reviewed every five years or sooner, thus assuring that they remain up-to-date consensus documents.

Although many of the microscopy standards relate to specific materials; e.g., D 629, "Standard Guide for the Microscopic Examination of Textile Fibers", many others relate to the microscope itself, such as E 883 "Standard Guide for Reflected-Light Photomicrography." A list of some of these microscope standards is given in Table 1.

Table 1-Some Standards Relating to Specimen Preparation and Operation of the Microscope

\begin{tabular}{|ll|}
\hline \multicolumn{2}{|c|}{ ASTM Designation and Short Title } \\
\hline E 3 & Preparation of Metallographic Specimens \\
\hline E 2015 & Preparation of Plastics and Polymers \\
\hline E 1920 & Preparation of Thermal Spray Coatings \\
\hline E 1558 & Electrolytic Polishing \\
\hline E 766 & SEM Magnification Calibration \\
\hline E 883 & Reflected Light Microscopy \\
\hline E 986 & SEM Beam Size Measurement \\
\hline E 1351 & Preparation of Replicas \\
\hline E 1951 & Calibration of Reticles and LOM Magnification \\
\hline E 175 & Terminology in Microscopy \\
\hline E 7 & Terminology in Metallography \\
\hline
\end{tabular}

\section{Standard Test Methods, Practices, and Guides}

Microscopists in specific fields, such as metallography, use standards every day, for measuring grain size, inclusions, etc. However, many microscopists are unaware of the many useful procedures defined within the large array of standards. The documents can be used to learn a procedure, and compute a measure of precision and bias, but they are also useful to show us how to report results in a standardized fashion for comparison among laboratories. Table 2 shows a list of procedural standards for various materials.

Table 2-List of Some Procedural Standards

\begin{tabular}{|ll|}
\hline \multicolumn{1}{|c|}{ Topic } \\
\hline E 562 & Point Counting \\
\hline E 1245 & Stereology \\
\hline E 45/1122 & Inclusion Rating \\
\hline E 112/1382 & Grain Size \\
\hline E 1181 & Duplex Grain Size \\
\hline E 1268 & Degree of Banding \\
\hline B 487 & Coating Thickness \\
\hline B 748 & Coating Thickness \\
\hline E 2283 & Extreme Value Analysis \\
\hline C 856 & Microscopy of Concrete \\
\hline D 629 & Microscopy of Textiles \\
\hline D 686 & Microscopy of Paper \\
\hline D 1030 & Microscopy of Paper \\
\hline D 2798 & Microscopy of Coal \\
\hline D 5061 & Microscopy of Coke \\
\hline D 3849 & EM of Carbon Black \\
\hline E 1588 & Gunshot Residue \\
\hline D 2109 & Thermal Spray Porosity \\
\hline F 1877 & Particle Characterization \\
\hline E 1090 & Clean Room Contaminants \\
\hline D 6281 & Asbestos \\
\hline
\end{tabular}

Although some of the standards in Table 2 were written for metals, they can be used for other specimens as well. For example, E 562 shows how to do point counting and gives guidance on how many points/fields are necessary for various degrees of precision. This procedure can be used to count voids, particles, grains, or biological features. In fact, the guidance in the standard can be used to measure the volume fraction of any discrete feature. E 1268 on banding, can be used to quantify lineations in any non-isotropic microstructure. The letter designations classify the subject of standards as shown in Table 3.

Table 3-Letter Designations of Standards

\begin{tabular}{|c|l|}
\hline A & Ferrous Metals \\
\hline B & Non-ferrous Metals \\
\hline C & Cement, Ceramics, Masonry \\
\hline D & Miscellaneous Materials \\
\hline E & Miscellaneous Subjects \\
\hline F & Materials for Specific Applications \\
\hline G & Degradation of Materials \\
\hline
\end{tabular}

\section{Standards for the SEM}

Many microscopy standards apply to the Light Optical Microscope (LOM), but it is interesting to note how many of them that are either specific to the SEM or include the SEM in their scope. A list of those pertaining to the SEM can be found in Table 4. Note that there is a standard under development that I called "E New", which seeks to standardize direct grain size measurement by EBSD. 


\section{Let Buehler Complete Your Circuit}

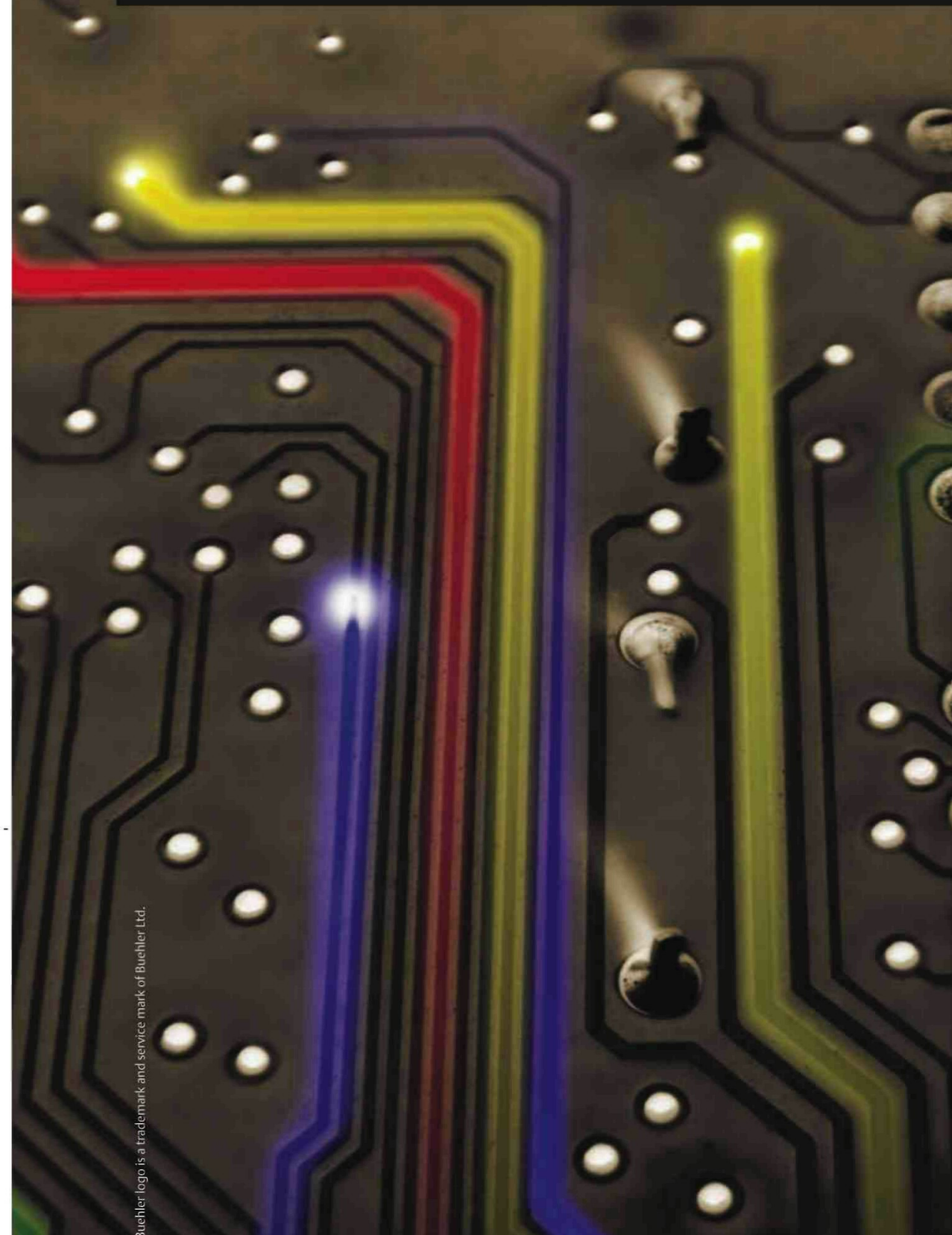

The importance of testing Printed Wiring Boards (PWBs) continues to increase as new electronic equipment enters the market, with increased function, new packaging and greater performance. Each step of the manufacturing process is critical, especially with smaller through-holes. Buehler is ready to meet your $R \& D$, testing and failure analysis needs with our new PWB Met Family of high precision through-hole cross-sectioning equipment.

\section{Flexibility}

A standard coupon sample can be removed anywhere on the PWB with Buehler's PWB Met Router. This is particularly useful for multilayer boards which are too thick for removal without inducing damage from a punch and die or when they cannot be removed on the production line. Routing ensures specimens that truly represent the manufacturing process.

\section{High Volume with Increased Accuracy}

Accurately pinpoint through-holes you wish to target for examination on the PWB Met Digital Alignment Drill. The onscreen alignment system allows your operator to easily align target holes, and automatically position drilling holes for the precision mounting pins. The PWB Met Small Hole Accessory cross-sections up to 18 coupons or 36 holes to target depth, quickly and effectively, thus providing enhanced productivity and cross-sectional accuracy for microvia holes as small as 4 mil $(100 \mu \mathrm{m})$.

\section{Meeting your Needs}

Whether cross-sectioning through-holes or preparing integrated circuits and discrete components, we have the complete solution for your electronics preparation. Buehler is your best connection.

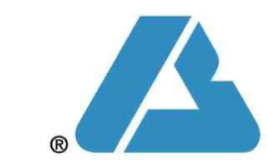

\section{BUEHLER}

Worldwide Headquarters

Buehler Ltd • 41 Waukegan Road • Lake Bluff, Illinois $60044 \bullet$ USA Tel: (847) 295-6500 • Fax: (847) 295-7979 Email: info@buehler.com•Web Site: http://www.buehler.com (An Emerson Industrial Automation subsidiary since 1992) 
Table 4-Standards Whose Scope Includes the SEM

\begin{tabular}{|c|c|l|}
\hline ASTM Desig. & Microscope & Topic \\
\hline E 562 & LOM/SEM & Point Counting \\
\hline E 766 & SEM & Magnification Calibration \\
\hline E 986 & SEM & Beam Diameter Measurement \\
\hline E 1245 & LOM/SEM & Stereology of 2nd Phases \\
\hline E 1268 & LOM/SEM & Degree of Banding \\
\hline E 2228 & LOM/SEM & Textile Fibers \\
\hline E 2090 & LOM/SEM & Clean Room Contaminants \\
\hline E 2283 & LOM/SEM & Extreme Value Analysis \\
\hline E 1508 & SEM & Guide to Quantitative EDS \\
\hline E 2015 & LOM/SEM & Polymer Specimen Prep \\
\hline E 2142 & SEM & Inclusions by SEM/EDS \\
\hline E 1588 & SEM & Gunshot Residue \\
\hline E 1877 & LOM/SEM & Particle Characterization \\
\hline E 748 & SEM & Coating Thickness \\
\hline E New & SEM & Grain Size by EBSD \\
\hline
\end{tabular}

\section{Grain Size Example}

An example of the usefulness of a standardized procedure to help us make a measurement may be found in duplex grain size analysis. The term duplex refers not only to bimodal distributions of grain diameters but to other specific duplex distributions as well. Some microstructures described in the E 1181 are illustrated in Fig. 1. Although these microstructural conditions are easily recognized, they would be difficult to describe without the examples and terminology shown in the standard, which goes on to describe how to select the specimens, make the measurements, and report the results. Moreover, it includes an annex of useful information.

\section{Banding Example}

Another example of a microstructure that could be hard to quantify is a banded anisotropic structure.

ALA (as large as)

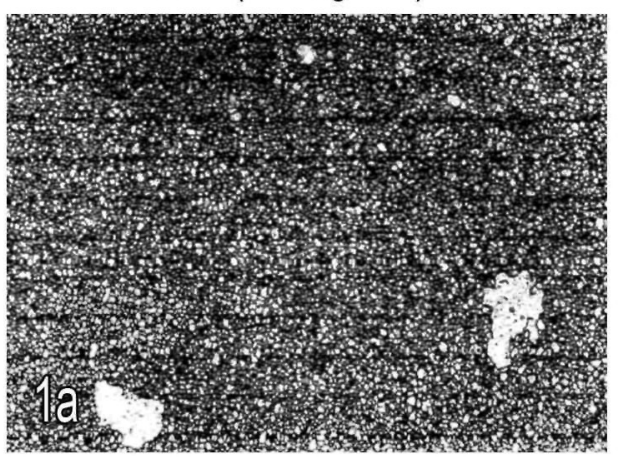

Necklace

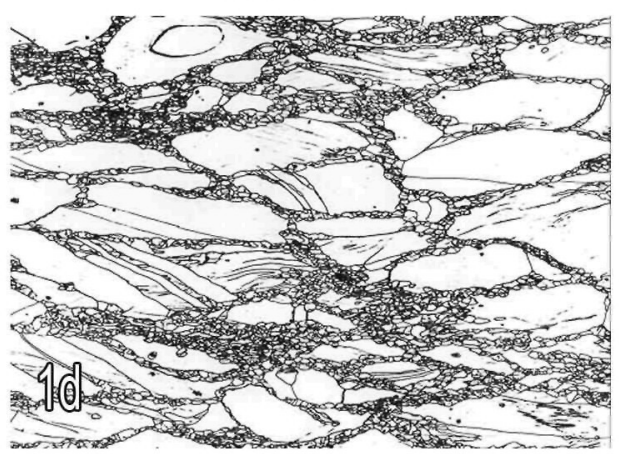

Wide Range

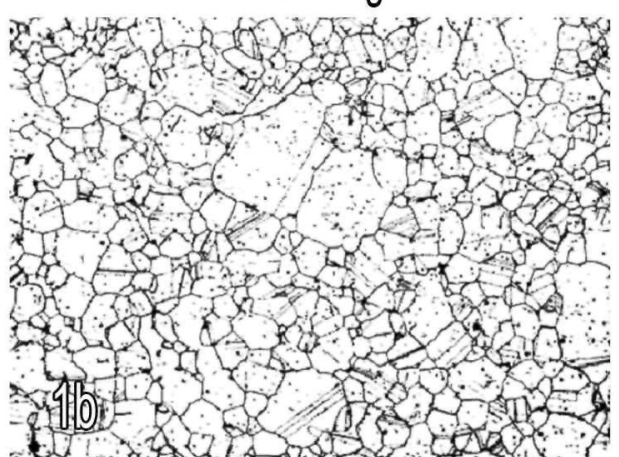

Banded

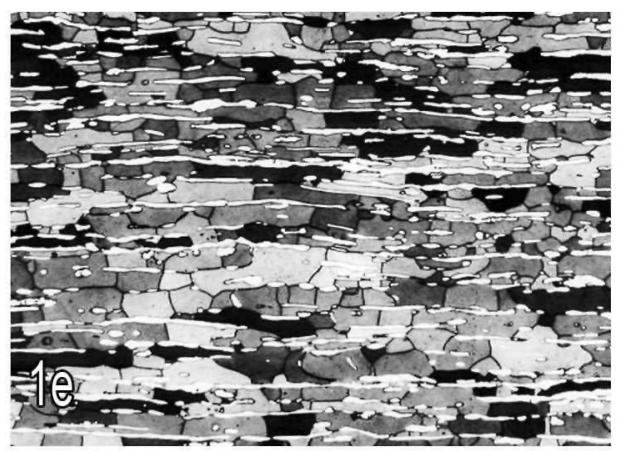

Consider the two structures in Fig. 2. They are clearly different, but how are we to quantify their degree of anisotropy? E 1268 gives us two measures. An Anisotropy Index (AI) is defined as:

$$
A I=\frac{N_{L \perp}}{N_{L P}}
$$

where $\mathrm{N}_{\mathrm{L}}$ refers to the number of perpendicular and parallel intercepts per unit length of test line.

The second measurement is called $\Omega_{12}$ and is defined as follows:

$$
\Omega_{12}=\frac{\bar{N}_{L \perp}-\bar{N}_{L \mathrm{P}}}{N_{L \perp}+0.571 N_{L \mathrm{P}}}
$$

These measurements provide a way of quantifying the degree of banding and making quantitative comparisons among microstructures. In a completely isotropic structure, $A I=1$ and $\Omega_{12}=0 . \mathrm{E} 1268$ provides specific guidance on specimen selection and preparation, making the measurements, and reporting the results.

\section{Quantitative EDS}

In the early 1990s, ASTM Subcommittee E04.11 on X-ray and Electron Metallography circulated a questionnaire to determine the need for a standard guide to quantitative EDS. The response was overwhelmingly positive, so the task group undertook an interlaboratory round-robin test program. The results were published as a Precision and Bias Section of the Guide. As of 2005, ASTM E 1508-Standard Guide to Quantitative Analysis by EDS has been revised twice and will be due for review again in two years. In addition to the Precision and Bias Section, the standard provides guidance for setting up for x-ray microanalysis, taking the data, and reporting the results. It even compares standardless methods with the use of compositional standards.

(1)

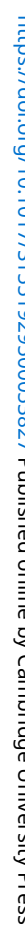




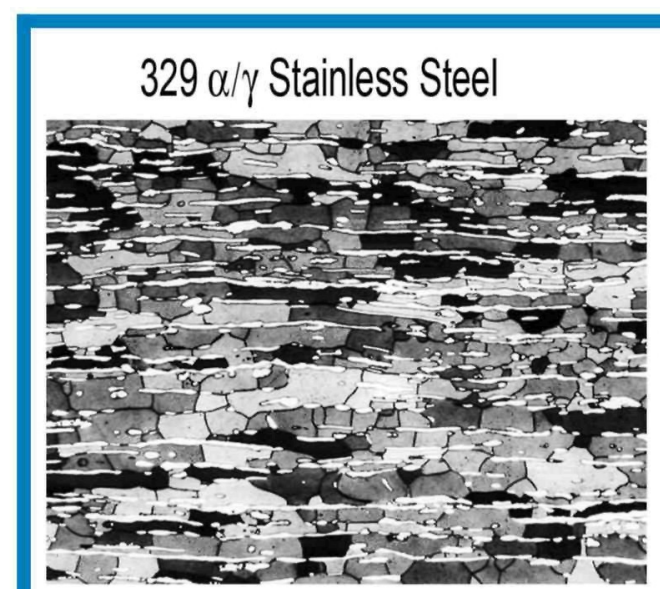

$\mathrm{Al}=1.67 \Omega_{12}=0.912$

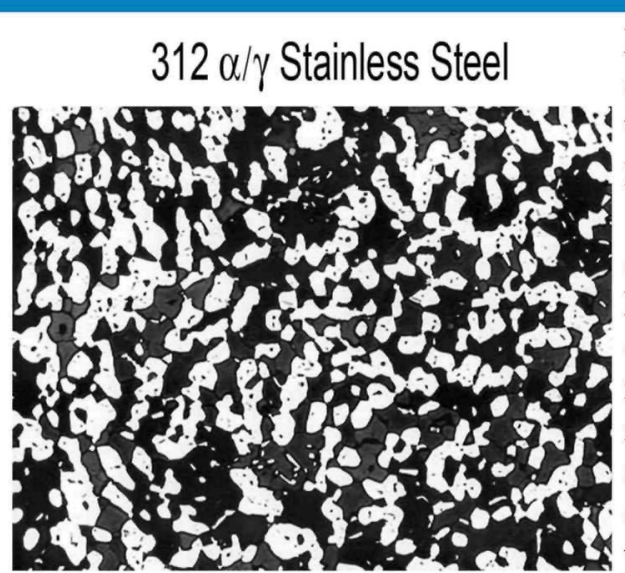

$A l=0.99 \Omega_{12}=-0.006$

Fig. 2-Comparison of banded and non-banded microstructures.

\section{Terminology}

Another class of ASTM standards that is often overlooked is terminology. These standards are produced by consensus of experts in their field and are the result of many hours of discussion and rounds of balloting until everyone is satisfied. They are more useful than a textbook glossary and are generally up-to-date. The most useful terminology standard in microscopy is E 7 "Standard Terminology in Metallography." Although the word metallography appears in the title, the terms are not restricted to metals, and in fact, there are 16 terms beginning with electron-as in electron microscopy. It also contains a list of acronyms and abbreviations, including MSA. Moreover, it is expanded whenever new words are needed and always more frequently than the five-year mandatory review.

\section{The ASTM International Organization}

As an organization, ASTM Intl. is composed of 134 Technical Committees, 2200 subcommittees, and over 30,000 members from 100 countries. All interests are represented, and although ASTM standards are used for accreditation, ASTM neither certifies nor accredits materials, products, systems, or services. A person does not have to be a member to participate in a Task Group, but membership is necessary for voting at the subcommittee or main committee level. The standards can be purchased from ASTM on their web site (www.astm.org), or they can be found in many libraries. Since libraries often do not keep a full collection of the latest volumes, it is wise to compare the version in the library with the latest version

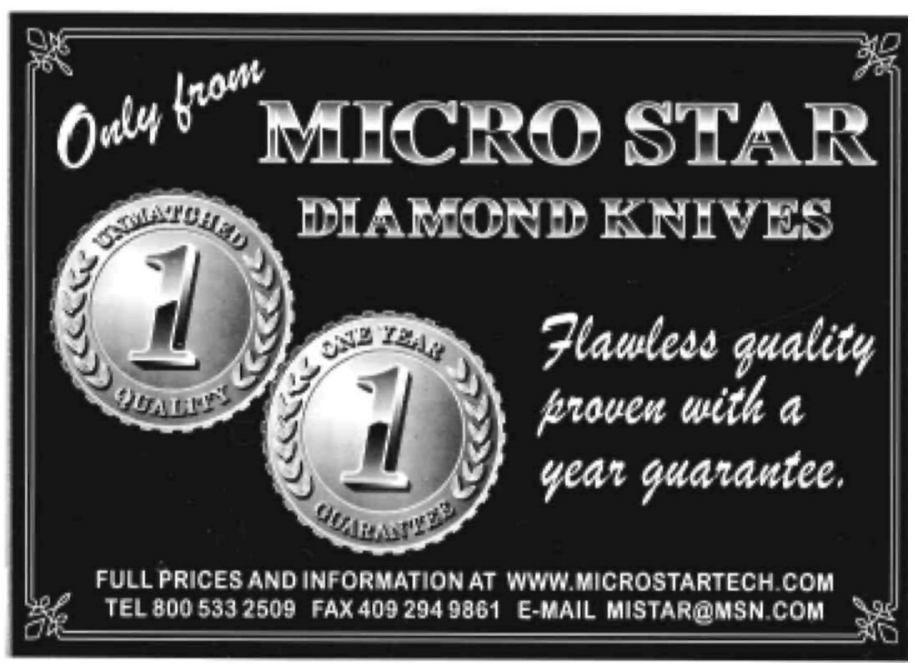

listed on the web site. The web site also has an extensive keyword search capability.

What if I Believe There is a Need for a New Standard?

Anyone can propose a new standard by contacting the chairman of the subcommittee having jurisdiction or ASTM International directly. The appropriate staff manager will forward the idea to the chairman. If a significant number of subcommittee members agree, then a Task Group will be formed with a Chairman and 5-10 members, including you, and work will begin. It may take a couple of years from inception to published standard, but if there is interest in the method, there will be interest in writing a standard. The work on grain size by EBSD started this way.

\section{Do I Need to Use Standards?}

ASTM standards can assist the microscopist in the following ways:

- Learn how to set up and perform a specific measurement.

- Find out the precision and bias of a technique.

- Learn the secrets of specimen selection and preparation for the microscopy of a specific material.

- Learn the accepted terminology in a given field.

- Conform to standard practice.

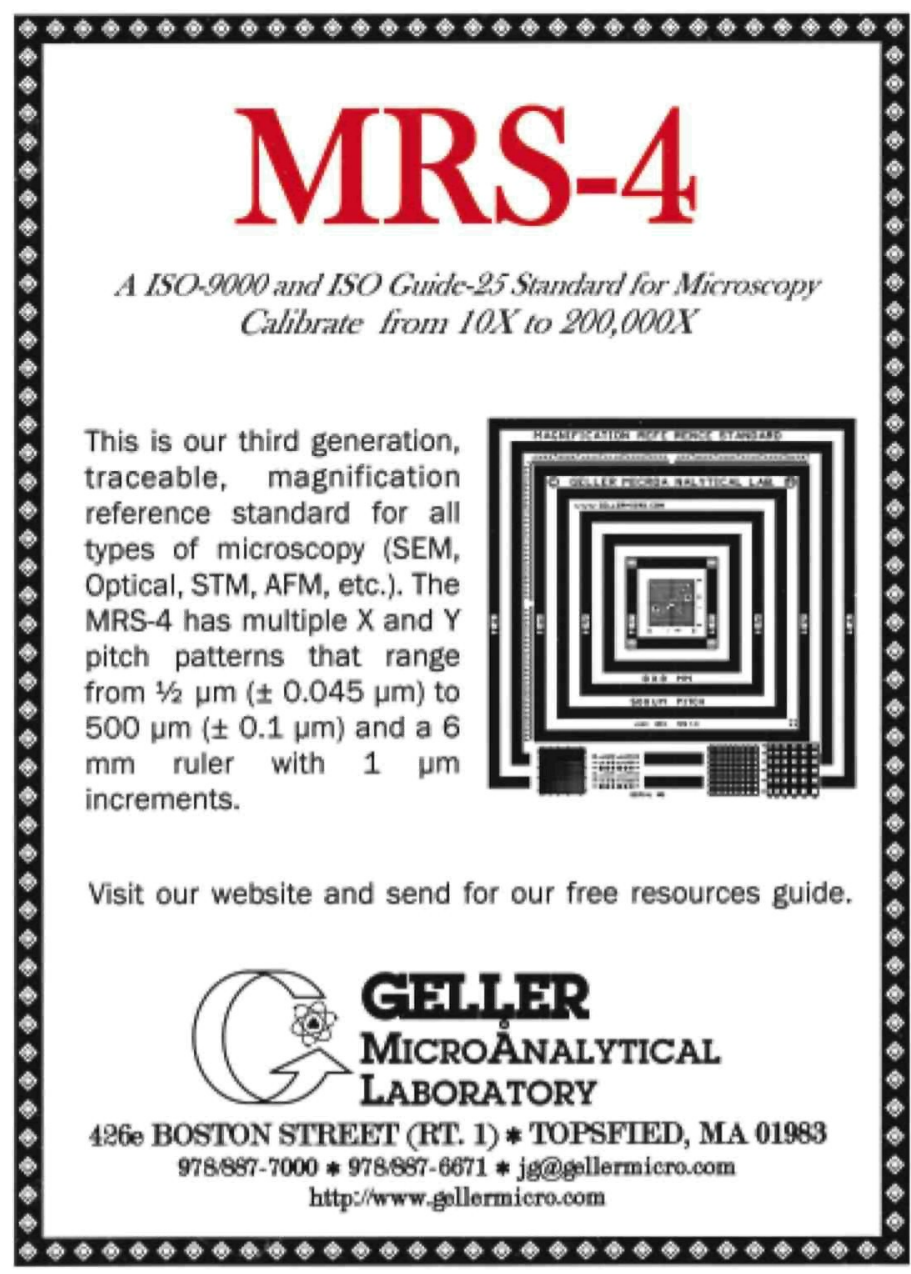

